\title{
Potential CO2 leakage reduction through biofilm-induced calcium carbonate precipitation
}

\section{Authors: Adrienne J. Phillips, Ellen Lauchnor, Joachim (Joe) Eldring, Richard Esposito, Andrew C. Mitchell, Robin Gerlach, Alfred B. Cunningham, and Lee H. Spangler}

NOTICE: This document is the unedited author's version of a Submitted Work that was subsequently accepted for publication in Environmental Science \& Technology, copyright (C) American Chemical Society after peer review. To access the final edited and published work, see http://dx.doi.org/10.1021/es301294q.

Phillips AJ, Lauchnor E, Eldring J, Esposito R, Mitchell AC, Gerlach R, Cunningham AB, Spangler $\mathrm{LH}$, "Potential CO2 leakage reduction through biofilm-induced calcium carbonate precipitation," Environmental Science \& Technology, January 2013 47(1): 142-149. 


\title{
Potential $\mathrm{CO}_{2}$ Leakage Reduction through Biofilm-Induced Calcium Carbonate Precipitation
}

\author{
Adrienne J. Phillips, ${ }^{*}, \dagger, \ddagger$ Ellen Lauchnor, ${ }^{\dagger}$ Joachim (Joe) Eldring, ${ }^{\dagger}$ Richard Esposito, ${ }^{\S}$ \\ Andrew C. Mitchell, ${ }^{\text {II }}$ Robin Gerlach, ${ }^{*},{ }^{\dagger},{ }^{\dagger}$ Alfred B. Cunningham, ${ }^{\dagger}$ and Lee H. Spangler ${ }^{\|}$ \\ ${ }^{\dagger}$ Center for Biofilm Engineering, 366 EPS Building, Montana State University, Bozeman, Montana 59717, United States \\ ${ }^{\ddagger}$ Chemical and Biological Engineering Department, 306 Cobleigh Hall, Montana State University, Bozeman, Montana 59717, United \\ States \\ ${ }^{\S}$ Southern Company Generation, P.O. Box 2641, BIN 14N-8195, Birmingham, Alabama 35291-8195, United States \\ IIInstitute of Geography \& Earth Sciences, Aberystwyth University, Llandinam Building, Penglais Campus, Aberystwyth, Ceredigion \\ U.K. SY23 3DB; \\ "Energy Research Institute, P.O. Box 172465, Montana State University, Bozeman, Montana 59717, United States
}

ABSTRACT: Mitigation strategies for sealing high permeability regions in cap rocks, such as fractures or improperly abandoned wells, are important considerations in the long term security of geologically stored carbon dioxide $\left(\mathrm{CO}_{2}\right)$. Sealing technologies using low-viscosity fluids are advantageous in this context since they potentially reduce the necessary injection pressures and increase the radius of influence around injection wells. Using aqueous solutions and suspensions that can effectively promote microbially

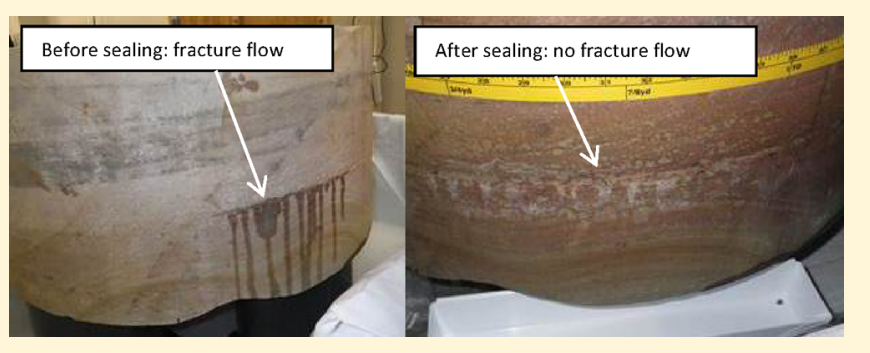
induced mineral precipitation is one such technology. Here we describe a strategy to homogenously distribute biofilm-induced calcium carbonate $\left(\mathrm{CaCO}_{3}\right)$ precipitates in a $61 \mathrm{~cm}$ long sandfilled column and to seal a hydraulically fractured, $74 \mathrm{~cm}$ diameter Boyles Sandstone core. Sporosarcina pasteurii biofilms were established and an injection strategy developed to optimize $\mathrm{CaCO}_{3}$ precipitation induced via microbial urea hydrolysis. Over the duration of the experiments, permeability decreased between 2 and 4 orders of magnitude in sand column and fractured core experiments, respectively. Additionally, after fracture sealing, the sandstone core withstood three times higher well bore pressure than during the initial fracturing event, which occurred prior to biofilm-induced $\mathrm{CaCO}_{3}$ mineralization. These studies suggest biofilm-induced $\mathrm{CaCO}_{3}$ precipitation technologies may potentially seal and strengthen fractures to mitigate $\mathrm{CO}_{2}$ leakage potential.

\section{INTRODUCTION}

Subsurface fractures may provide leakage pathways for geologically sequestered $\mathrm{CO}_{2}$. Whether fractures are initiated intentionally by hydraulic fracturing to alter subsurface flow conditions (i.e., improving fossil fuel extraction), unintentionally during drilling or pumping fluids into reservoirs, or exist because of natural formation conditions, fractures can play a significant role in the determination of geologic reservoir permeability and fluid flow pathways. ${ }^{1,2}$ As such, high permeability fractures in cap rock or even microfractures associated with well cements may contribute significantly to reservoir leakage potential. ${ }^{3,4}$

Ideally, potential $\mathrm{CO}_{2}$ storage sites are not connected to drinking or agricultural water aquifers and generally, functional aquifers are also separated from target storage reservoirs by low permeability cap rocks. Nevertheless, concerns exist regarding the impact of potential $\mathrm{CO}_{2}$ migration into overlying aquifers and the atmosphere. ${ }^{5,6}$ Leakage could result in carbon credit forfeiture under a carbon trading system, wasted resources or energy associated with the injection of $\mathrm{CO}_{2}$, pose a hazard to overlying functional water aquifers or endanger public health. ${ }^{3,5,6}$ Thus, primary leakage prevention or mitigation is essential to managing risks associated with subsurface $\mathrm{CO}_{2}$ storage.

Reducing the permeability of leakage pathways with biofilm has been previously investigated with promising results. ${ }^{7}$ The advantage to the use of microorganisms is their penetrability into small apertures, ${ }^{8}$ which may not be possible with higher viscosity sealing cements, making small fractures a target for biofilm sealing. The disadvantage to biofilm sealing technologies is the maintenance of established barriers; microbial 
biofilms will degrade over time without nutrient supply. However, a novel strategy using ureolysis-driven biofilminduced $\mathrm{CaCO}_{3}$ precipitation to mitigate fluid or gas leakage from subsurface reservoirs has been investigated. ${ }^{9}$ With biofilminduced $\mathrm{CaCO}_{3}$ precipitation, a stable mineral can remain even after biofilm has dispersed or nutrient addition has ceased.

Many microorganisms are capable of hydrolyzing urea enzymatically, which can influence the saturation state $(S)$ of surrounding fluids in the presence of calcium to favor precipitation (when $S>1$ ) of $\mathrm{CaCO}_{3}$ (eqs 1 and 2). ${ }^{10-13}$

$$
\begin{aligned}
& \mathrm{CO}\left(\mathrm{NH}_{2}\right)_{2}+2 \mathrm{H}_{2} \mathrm{O} \stackrel{\text { urease }}{\longrightarrow} 2 \mathrm{NH}_{4}{ }^{+}+\mathrm{CO}_{3}{ }^{2-} \\
& \mathrm{Ca}^{2+}+\mathrm{CO}_{3}{ }^{2-} \leftrightarrow \mathrm{CaCO}_{3}(\mathrm{~s})
\end{aligned}
$$

Microbial or biofilm-induced $\mathrm{CaCO}_{3}$ precipitation (MICP) via the urea hydrolysis pathway has been well explored for use in many technologies including: sealing cement fractures, forming protective surface layers, or strengthening cement; ${ }^{14}$ controlling flow in permeable zones or channels; ${ }^{15,16}$ and consolidating porous media, among other applications. ${ }^{17}$ These MICP technologies are widely researched across multiple disciplines, multiple scales (from micro to macro), and the understanding of treatment control and extent is rapidly advancing. ${ }^{18}$ For example, it was previously observed that MICP can produce nonhomogeneous distribution of $\mathrm{CaCO}_{3}$ which may lead to injection point plugging, limiting the spatial extent of the treatment. ${ }^{19,20}$ Researchers speculated more homogeneous distribution could be achieved by balancing the transport of reactants with the reaction rates or improving distribution of cells. ${ }^{19}$ These hypotheses were acknowledged and utilized to investigate an injection strategy leading to more homogeneous $\mathrm{CaCO}_{3}$ distribution in the research reported here.

The overall objective of this work was to investigate whether biofilm-induced $\mathrm{CaCO}_{3}$ mineralization could be scaled from a $61 \mathrm{~cm}$ laboratory sand-filled column to sealing a fractured 74 $\mathrm{cm}$ diameter sandstone core. Specific objectives were to (a) develop a new injection strategy in a sand-filled column to minimize injection point precipitation and promote homogeneous spatial distribution of $\mathrm{CaCO}_{3}$ while reducing permeability and (b) demonstrate that MICP technology is suited to sealing fractures, which could contribute to the leakage of geologically stored $\mathrm{CO}_{2}$. To this end, the injection strategy developed in the column study was used to twice seal and significantly strengthen a hydraulic fracture under radial flow and ambient pressure conditions in a Boyles Sandstone core. The primary novel aspect of this work is that $\mathrm{CaCO}_{3}$ distribution is controlled by manipulating the $\mathrm{CaCO}_{3}$ saturation conditions in time and space. This time and space dependent control of the $\mathrm{CaCO}_{3}$ saturation index can be applied to real world systems to promote homogeneous distribution of $\mathrm{CaCO}_{3}$ along the direction of flow and minimize near-injection-point plugging.

\section{EXPERIMENTAL METHODS}

Bacterial Cultivation. Cultures of Sporosarcina pasteurii, a ureolytically active organism, were grown overnight from frozen stock cultures to stationary phase, washed via centrifugation, and resuspended in fresh sterile medium to an OD600 of 0.4 prior to column or fracture inoculation.

Column Experiment. Results from column experiments 1-4 were previously reported in Cunningham et al. (2011) and Ebigbo et al. (2012). Similar to those experiments, column 5 was prepared by packing a $61 \mathrm{~cm}$ long, $2.54 \mathrm{~cm}$ diameter column with sand, followed by disinfection and rinsing (Supporting Information). Growth (ionic strength $0.2 \mathrm{M}$ ) and calcium-growth (ionic strength $1.2 \mathrm{M}$ ) media were prepared as previously described (Supporting Information) and a calciumand urea-free (displacement) medium (ionic strength $0.2 \mathrm{M}$ ) was prepared with $3 \mathrm{~g} / \mathrm{L}$ Difco Nutrient Broth, $10 \mathrm{~g} / \mathrm{L}$ ammonium chloride (Fisher, NJ, USA), and $100 \mathrm{~mL} / \mathrm{L}$ glycerol (EMD Chemicals, NJ, USA) to minimize media density differences. Media densities were confirmed by comparing the masses of known volumes and media viscosities were measured using a TA Instruments AR-G2 rotational rheometer. Column 5 was inoculated and a postinoculation cell-attachment period (no flow) of approximately $6 \mathrm{~h}$ was followed by $18 \mathrm{~h}$ of biofilm promotion by continuously injecting growth medium as previously described. ${ }^{21,22}$ Then, the column was flushed with calcium- and urea-free medium between biomineralizing stages to establish a low saturation state and minimize instantaneous precipitation when calcium-growth medium was injected. Finally, two pore volumes of calcium-growth medium ( 0.33 $\mathrm{M}$ equimolar calcium/urea) were injected to initiate $4-8 \mathrm{~h}$ static biomineralization stages (Table 1). The first $7.6 \mathrm{~cm}(3$

Table 1. Calcium Deposition Efficiency and Permeability Reduction in Five Column Experiments

\begin{tabular}{cccccc}
$\begin{array}{c}\text { displace } \\
\text { calcium } \\
\text { in } \\
\begin{array}{c}\text { column } \\
\text { no. }\end{array}\end{array}$ & $\begin{array}{c}\text { calcium } \\
\text { region? } \\
\text { concentration } \\
\text { in medium } \\
(\mathrm{M})\end{array}$ & $\begin{array}{c}\text { calcium } \\
\text { deposition } \\
\text { efficiency }\end{array}$ & $\begin{array}{c}\text { reduction in } \\
\text { permeability } \\
(\mathrm{md})\end{array}$ & $\begin{array}{c}\text { column } \\
\text { plugged? }\end{array}$ \\
$1^{21,22}$ & no & 1.25 & $13 \%$ & $66 \%$ & yes \\
$2^{22}$ & yes & 1.25 & $24 \%$ & $99 \%$ & yes \\
$3^{22}$ & yes & 1.25 & $29 \%$ & $89 \%$ & yes \\
$4^{22}$ & yes & 1.25 & $15 \%$ & $72 \%$ & no \\
5 & yes & 0.33 & $71 \%$ & $61 \%$ & no \\
\hline
\end{tabular}

in.) of the column were replaced with displacement medium immediately after injection of the calcium-growth medium to minimize injection point $\mathrm{CaCO}_{3}$ precipitation. During the column 5 experiment, biofilm was resuscitated by injecting fresh growth medium without $\mathrm{Ca}^{2+}$ every afternoon for overnight growth as opposed to the periodic, unscheduled resuscitation events reported in columns $1-4 .^{21,22}$

Injection flow rates were controlled by a Masterflex (Model 7553-70) pump and controller (Cole Parmer, IL, U.S.A.) and differential pressures were monitored with water-filled piezometers to assess changes to column permeability. At the termination of the experiment, the column was destructively sampled to determine mass of calcium associated per gram of sand along the column's axis of flow. ${ }^{21,22}$

Column and Core Fracture Residual Effluent Analysis. Column and fracture biomineralization stage effluents were collected and monitored for ammonium $\left(\mathrm{NH}_{4}^{+}\right)$, an indication of ureolysis, and residual $\mathrm{Ca}^{2+}$ concentration. A filtered portion of the effluent sample was analyzed with a modified Nessler assay for $\mathrm{NH}_{4}^{+}$production ${ }^{21,22}$ and ion chromatography (Metrohm, USA) to monitor dissolved $\mathrm{Ca}^{2+}$ concentration (Supporting Information). The unfiltered remainder of the effluent sample was used to monitor $\mathrm{pH}$ and the number of culturable cells using a drop plate enumeration method. ${ }^{23}$

Core Drilling and Characterization. A $74.3 \mathrm{~cm}$ diameter, $37.5 \mathrm{~cm}$ tall Boyles Sandstone (member of the Lower Pottsville Formation, a potential sequestration formation identified by 
Southern Company, AL, USA) core was obtained from Etowah County, Alabama (Russo Corp, AL, USA) (Figure 1). While

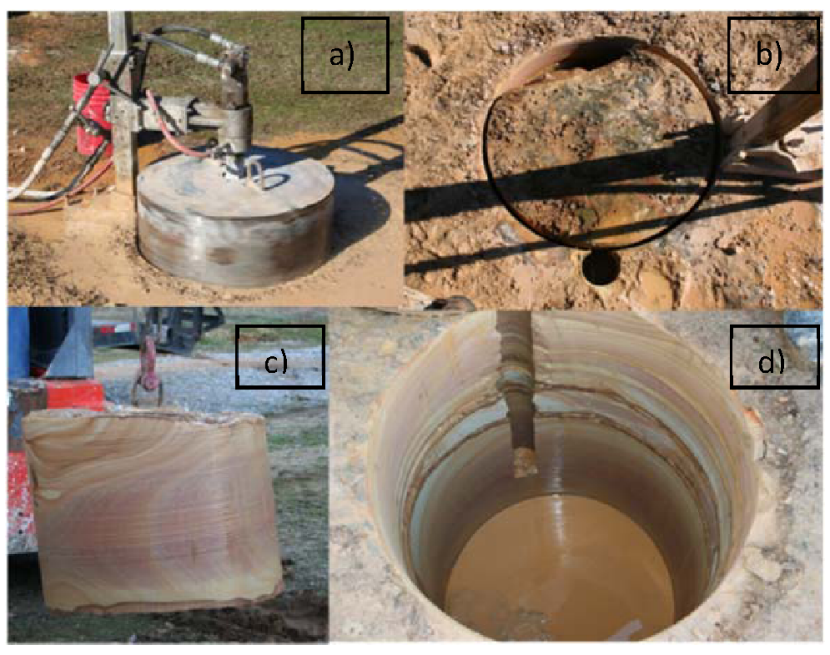

Figure 1. $(a-d)$ Photos showing the progression of drilling and extraction of the Boyles Sandstone core. (a) The core was drilled using a $76.2 \mathrm{~cm}$ diameter core drill under water cooling to the depth of $\sim 100$ $\mathrm{cm}$; (b) a secondary $10.2 \mathrm{~cm}$ core was drilled adjacent to the large bore to break the core from the underlying formation with a pneumatic pump; (c) a metal plate was attached to holes drilled into the top of the core; and (d) the core was lifted free of the formation.

some unidentified artifacts associated with surface weathering may be present with the core drilled at ground surface, the Boyles Sandstone was chosen due to its presence at relevant sequestration depths in the Pottsville formation. After drilling, a slab saw was used to cut the core to height and a $5.1 \mathrm{~cm}(2 \mathrm{in}$.) hole was drilled through the core's center.

Samples of the cored sandstone material were sent to the University of Alabama at Birmingham, Department of Mechanical Engineering, for permeability and minimum capillary displacement pressure measurements (Supporting Information). A portion of the core material was also analyzed for porosity and pore structure characterization via mercury porosimetry (Micromeritics AutoPore IV 9500 Series, GA, USA) at University of Montana, Montana Tech's Center for Advanced Mineral Processing in Butte, Montana, USA (Supporting Information). Thin section analysis for mineralogy and porosity was performed at the Geological Survey of Alabama, USA (Figure S1, Supporting Information).

Core Injection System Design. A Teledyne Isco pump and controller (Teledyne, NE, USA) were used to inject fluids either under constant flow or pressure control (Figure 2a) through flexible stainless steel tubing and stainless fittings 0.635 cm ID (1/4 in.) (Swagelok, USA). An expandable double packer assembly was constructed from a threaded rod, spacers, washers, nuts, and rubber elements (Supporting Information). The core was placed in a lined shipping crate on blocks to allow for effluent fluid collection and the packer assembly was installed to isolate a zone between 7.6 and $15.2 \mathrm{~cm}$ from the bottom of the core.

Core Initial Hydraulic Fracturing Event. The core's hydraulic behavior was initially characterized by injecting water under radial flow conditions and recording flow and pressure via the Teledyne Isco pump Labview interface (National Instruments, TX, USA). Water was injected at constant pressure ( 8 bar) for approximately $1.75 \mathrm{~h}$ before the rock

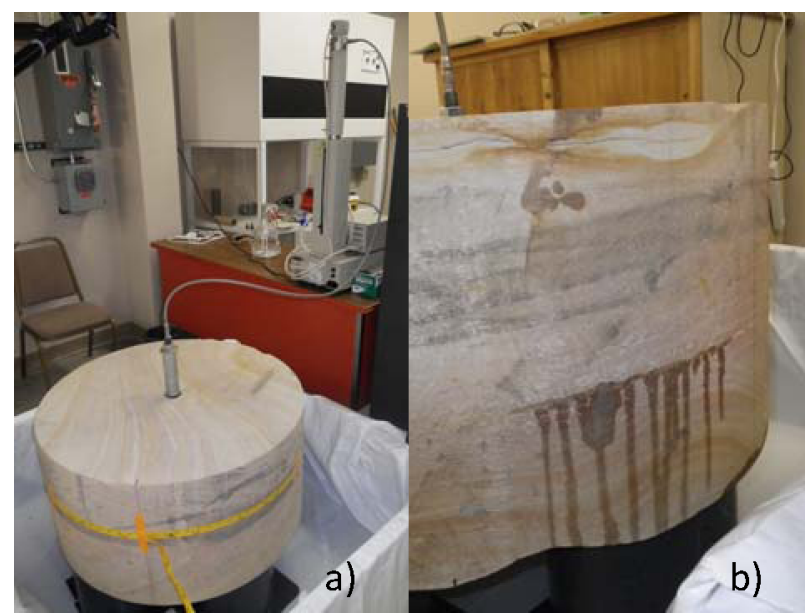

Figure 2. Images of injection system and flow path from the fracture. (a) Fluids were injected in radial flow configuration to the Boyles Sandstone core via double packer system with a Teledyne Isco pump. (b) Original channel-like flow path was observed from the hydraulic fracture.

hydraulically fractured along a horizontal bedding plane perpendicular to the well bore (Figure $2 \mathrm{~b}$ ). The fracture occurred approximately $15.9 \mathrm{~cm}$ from the bottom of the core, measured approximately $1 \mathrm{~mm}$ in thickness, and extended approximately $33 \mathrm{~cm}$ in length on the outside circumference of the core.

Core Fracture Sealing Experiments. For each sealing experiment, the pump, influent tubing and packer were disinfected; growth medium was injected to condition the core; and $35 \mathrm{~mL}$ of a $S$. pasteurii cell suspension (cell concentrations: $2.3 \times 10^{7} \mathrm{cfu} / \mathrm{mL}$ experiment \#1, $3.8 \times 10^{7}$ $\mathrm{cfu} / \mathrm{mL}$ experiment 2) was filled into the packer for fracture inoculation. Growth medium was pumped at $20 \mathrm{~mL} / \mathrm{min}$ to push the cells into the fracture, and fracture effluents were collected to confirm microbial penetration (effluent concentration measured: $2.6 \times 10^{5} \mathrm{cfu} / \mathrm{mL}$ sealing experiment $1,3.2 \times$ $10^{6} \mathrm{cfu} / \mathrm{mL}$ sealing experiment 2 ). Cell-attachment periods (no flow) of 4-5 h were followed by $18 \mathrm{~h}$ of continuous growth medium flow to promote biofilm development. At least two fracture pore volumes of urea- and calcium-free medium were then injected to restore low $\mathrm{CaCO}_{3}$ saturation states to minimize immediate precipitation. Next, greater than two pore volumes of $0.33 \mathrm{M}$ (equimolar $\mathrm{Ca}^{2+}$ and urea) calcium-growth medium (ionic strength 1.2M) amended with $0.04 \mathrm{~g} / \mathrm{L}$ fluorescein (Acros, NJ, USA) were injected to initiate biomineralization. Lastly, fluids in the fracture's first $5.4 \mathrm{~cm}$ were replaced with displacement medium to minimize injection point mineralization.

At the beginning of sealing experiment 1 , after injection of the calcium-growth medium, $24 \mathrm{~h}$ static biomineralization stages were performed. However, this strategy led to evaporative drying of the core overnight which was hypothesized to contribute to reduced ureolytic activity because of desiccation of the biofilm. Hence, on day 14, growth medium was injected at $0.69 \mathrm{~mL} / \mathrm{min}$ overnight to reduce drying and resuscitate ureolytic biofilm activity. During sealing experiment 2 , similar injection strategies were utilized except growth medium was injected overnight immediately to minimize evaporative drying. During sealing experiment 2, two calciumgrowth media pulses were performed daily (with $\sim 4 \mathrm{~h}$ biomineralization stages) in an effort to speed up sealing. 


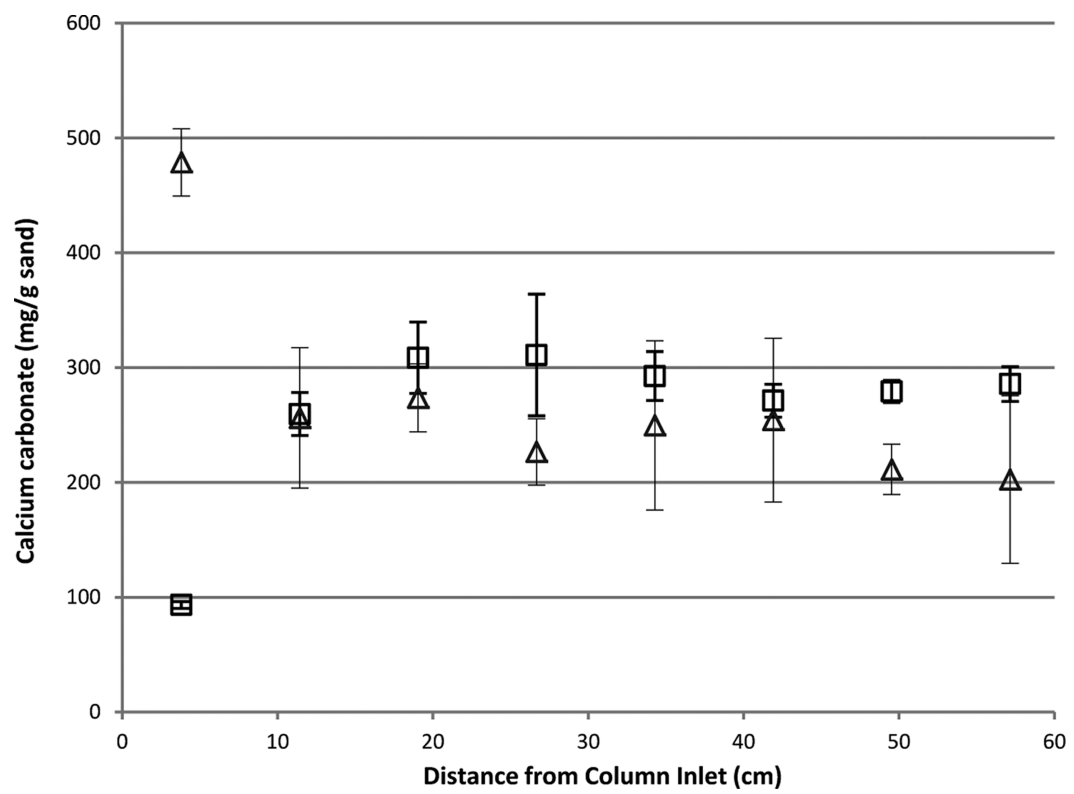

Figure 3. $\mathrm{CaCO}_{3}$ concentration (mg per gram of sand) with error bars representing the standard deviation of measured calcium by ICP-MS in vertically positioned column experiments $\left(\Delta\right.$, column $1 ; \square$, column 5). Reduced $\mathrm{CaCO}_{3}$ in the near-injection-point (93 $\pm 3 \mathrm{mg} / \mathrm{g}$ sand) was measured in column 5 (near-injection-point displacement strategy employed) as compared to column 1 (478 $\pm 29 \mathrm{mg} \mathrm{CaCO} / \mathrm{g}_{3}$ sand). Adapted from Ebigbo et al. (2012) and Cunningham et al. (2011).21,22.

In the core sealing experiments, the pump was initially operated in constant flow mode at $20 \mathrm{~mL} / \mathrm{min}$. However, as the fracture sealed, pressures exceeded the pump's shut off pressure set-point of 7 bar in sealing experiment 1 and 8 bar in sealing experiment 2 . These set-points were designed to minimize the risk of refracturing during sealing experiments. Thus, for the experiments' remainder, the pump was operated in constant pressure mode in which the pump internally adjusts flow to maintain pressure rather than constant flow mode. Influent pressure $(p)$ and flow rate $(Q)$ were recorded using the Isco pump's Labview interface.

Prior to injection of calcium-growth medium in sealing experiment 1, the fracture zone region on the outside circumference of the core was scraped with a disinfected stainless steel rod and particles collected as a control for XRD analysis. At the termination of the experiment, the inside of the well bore and the outside of the core in the fracture zone were also scraped and particles were analyzed by XRD to determine mineral phases present (Supporting Information Figure S2).

The packer was twice removed to observe well bore and packer conditions and confirm the packer was not clogged with $\mathrm{CaCO}_{3}$. Well bore images were collected with a digital endoscope equipped with a reflector tube (Oasis Scientific, SC, USA) (Supporting Information Figure S3). The packer was cleaned, disinfected and reinserted to the original location isolating the fracture zone.

Sealed Fracture Strength Testing. Core sealing experiment \#1 was terminated by testing the strength of the sealed fracture by injecting water amended with fluorescein using stepwise increasing pressures ( 8 bar up to $30 \mathrm{bar}$ ). Two parameters were measured: injection pressure $(p)$ and flow $(Q)$ using the Isco pump's Labview interface. Images were collected under black light to visualize breakthrough of the injected fluid (Supporting Information Figure S5).

\section{RESULTS}

Injection Strategy to Produce Homogenous $\mathrm{CaCO}_{3}$ Distribution. Column $\mathrm{CaCO}_{3}$ Distribution. Aside from the near-injection-point region of the previously reported sandfilled columns, a relatively homogeneous distribution of $\mathrm{CaCO}_{3}$ was achieved along the axis of flow (Figure 3). ${ }^{21,22}$ The first iteration of column experiments (column 1) did not employ near-injection-point calcium displacement and the $\mathrm{CaCO}_{3}$ concentration per gram of sand was significantly higher near the injection point than in subsequent column experiments. ${ }^{21,22}$ Beyond the first $7 \mathrm{~cm}$, relatively homogeneous distribution along the flow path was achieved, particularly in column 5 (Figure 3). Column 5's injection strategy included the use of equimolar ratios of urea and $\mathrm{Ca}^{2+}$ in the media, near-injectionpoint rinsing during biomineralization stages, and regularly scheduled resuscitation events. This evolved strategy served to produce a low influent region $\mathrm{CaCO}_{3}$ concentration to minimize near-injection point plugging and homogeneous distribution of $\mathrm{CaCO}_{3}$ over the rest of the column. While the contribution of bacteria to the reduction in pore space was not quantified, at the end of the Column 5 experiment calcite was calculated to occupy an average of $15.4 \%$ of the $47 \%$ porosity of the sand pack.

Core Fracture $\mathrm{CaCO}_{3}$ Distribution. Radial distribution of precipitates in the core fracture experiments could not be quantitatively determined without destructive core sampling (undesirable since further experiments are planned). Despite this limitation, visual observation of the well bore revealed apparent $\mathrm{CaCO}_{3}$ precipitation, as compared to regions without treatment (Supporting Information Figure S3a and b). Additionally, calcite was detected via XRD from the scraping of the fracture region on the core's exterior (Supporting Information Figure S2b) and from scrapings of the well bore post experiment (data not shown). While it could not be quantitatively demonstrated that $\mathrm{CaCO}_{3}$ formed homogeneously along the length of the fracture, qualitative evidence (visual observation and the positive calcite detection with 
XRD) suggests that $\mathrm{CaCO}_{3}$ precipitated at least inside the well bore and outside the fracture (i.e. at the beginning and end of the flow path).

Residual-Effluent Analysis. Column Ureolysis. As previously reported, column experiments 1-4 did not employ regular biofilm resuscitation events but rather resuscitation was initiated when effluent $\mathrm{NH}_{4}^{+}$concentrations were observed to decrease to as low as $5.1 \mathrm{~g} / \mathrm{L} .^{21,22}$ In the column 5 experiment, resuscitation events were performed nightly which contributed to maintaining an active ureolytic population and high effluent $\mathrm{NH}_{4}{ }^{+}$concentrations. Effluent $\mathrm{NH}_{4}{ }^{+}$concentrations averaged $13.3 \pm 3.3 \mathrm{~g} / \mathrm{L}$.

Core Fracture Ureolysis. On the basis of low average effluent $\mathrm{NH}_{4}{ }^{+}$concentrations $(4.6 \pm 2.4 \mathrm{~g} / \mathrm{L})$ in core sealing experiment 1's first 13 days of treatment, it was hypothesized that evaporative drying between biomineralizing injections was negatively impacting the $S$. pasteurii biofilm, reducing the ureolytic activity, and thereby reducing $\mathrm{Ca}^{2+}$ precipitating activity. ${ }^{24}$ As such, on the 14 th day of sealing experiment \#1, the injection strategy was modified to include an overnight growth pulse to minimize desiccation and revive biofilm ureolytic activity. After day 14, it was consistently observed that the average $\mathrm{NH}_{4}^{+}$concentration $(12.8 \pm 1.2 \mathrm{~g} / \mathrm{L})$ and effluent culturable cell numbers were greater after initiating overnight biofilm resuscitation events (Figure S4 Supporting Information).

Column Calcium. The columns' $\mathrm{Ca}^{2+}$ deposition efficiency was calculated as the sum of the mass of $\mathrm{Ca}^{2+}$ measured in each column section determined from inductively coupled plasma mass spectrometry (ICP-MS) divided by the total known mass of $\mathrm{Ca}^{2+}$ injected. Columns 1-4 utilized biomineralizing media with $1.25 \mathrm{M}$ calcium and $0.33 \mathrm{M}$ urea where $\mathrm{Ca}^{2+}$ deposition efficiency was limited by the production of $\mathrm{CO}_{3}{ }^{2-}$ from ureolysis and complete $\mathrm{Ca}^{2+}$ precipitation could not be achieved. $^{21,22}$ The injection strategy employed for column 5 involved using equimolar concentrations of urea and $\mathrm{Ca}^{2+}$ $(0.33 \mathrm{M})$ in the biomineralizing solutions and regularly resuscitating the biofilm with growth medium. This, as predicted, yielded greater overall $\mathrm{Ca}^{2+}$ precipitation efficiency (Table 1).

Core Fracture Calcium. For the core fracture sealing experiments, evolved injection strategies using media with equimolar concentrations of $\mathrm{Ca}^{2+}$ and urea $(0.33 \mathrm{M})$ and regularly scheduled resuscitation events were utilized (beyond day 14 in experiment 1). Calcium deposition efficiency was calculated by comparing the differences between known injected $\mathrm{Ca}^{2+}$ mass and the residual-effluent $\mathrm{Ca}^{2+}$. In sealing experiment 1 as much as $93 \%$ and in sealing experiment 2 as much as $86 \%$ of the injected $\mathrm{Ca}^{2+}$ was estimated to have been deposited.

Permeability. Column Permeability. Column flow rate and differential pressure were recorded to calculate hydraulic conductivity (eq 3) which was converted to permeability using measured fluid density and viscosity (eq 4). ${ }^{25} \mathrm{~K}$ is hydraulic conductivity, $Q$ is measured flow rate, $\Delta p$ is differential pressure, $A$ is cross-sectional column area (5.1 $\left.\mathrm{cm}^{2}\right), L$ is column length $(61 \mathrm{~cm}), k$ is permeability, $\mu$ is dynamic viscosity $\left(1.29 \times 10^{-3}, 1.01 \times 10^{-3}, 1.05 \times 10^{-3} \mathrm{~kg} / \mathrm{m}\right.$ $\mathrm{s}$ displacement medium, growth medium, calcium growth medium, respectively), $\rho$ is density $\left(1013 \mathrm{~kg} / \mathrm{m}^{3}\right)$, and $g$ is the acceleration of gravity $\left(9.81 \mathrm{~m} / \mathrm{s}^{2}\right)$.

$$
\begin{aligned}
& Q=-K A \frac{\Delta p}{L} \\
& k=\frac{K \mu}{\rho g}
\end{aligned}
$$

The permeability of the columns was reduced by $61-99 \%$ (Table 1 ) as compared to $0 \%$ in previously studied control columns either not inoculated with microbes or inoculated with a nonureolytic strain of Bacillus subtilis. ${ }^{21,26}$ Variations in these values were attributed to not all columns being plugged or not reaching system pressure limits when destructive sampling occurred. Please note: the prescribed goal of these experiments was development of methods to produce homogeneous distribution of $\mathrm{CaCO}_{3}$ along the flow length of the columns, not to plug the columns or determine the maximum reduction in permeability achievable.

Core Fracture Permeability. Fracture hydraulic conductivity was calculated using an equation for radial Darcy flow in confined aquifers. ${ }^{25}$ To calculate conductivity of the fracture when flow was preferential through the fracture, the equation was modified to scale from full radial flow to fracture only radial flow by multiplying the $2 \pi$ term with the fracture length to core circumference ratio (eq 5 ), where $b_{1}$ is approximate fracture aperture, $b_{2}$ is effective width of screened area in the packer, $r_{\mathrm{o}}$ is the radial extent of the fracture at the outside of the core, and $r_{\mathrm{w}}$ is the radius of the well. After day 23 (sealing experiment 1 ) and day 5 (sealing experiment 2), conductivity was calculated with the equation restored to its original form as fluids stopped flowing through the fracture preferentially and radial flow was observed (eq 6).

$$
\begin{aligned}
& K=Q \frac{\ln \left(\frac{r_{0}}{r_{\mathrm{w}}}\right)}{\left(\frac{\text { fracturelength }}{\text { corecircumference }}\right) 2 \pi \Delta p b_{1}} \\
& K=Q \frac{\ln \left(\frac{r_{0}}{r_{\mathrm{w}}}\right)}{2 \pi \Delta p b_{2}}
\end{aligned}
$$

We assume (1) constant fracture aperture, (2) wellbore flow into the matrix is negligible compared with the fracture flow (until full radial flow is restored), (3) the ratio of the fracture's inner circumference to inner well bore circumference is the same as the outer fracture circumference to total core circumference, (4) fracture flow is horizontal and any vertical fracture flow is negligible, and (5) fracture roughness is neglected. ${ }^{27}$ The calculated conductivity was converted to permeability using measured fluid viscosity and density parameters via eq 4 (Figure 4).

After sealing experiment 1 , the sealed fracture strength was assessed with a second hydraulic fracture event. Pressures applied to the well bore were increased stepwise (8-30 bar) over the course of $1.6 \mathrm{~h}$ until fluids were observed flowing from the fracture. The flow rate of water increased from 1.5 to 160 $\mathrm{mL} / \mathrm{min}$ as the differential pressure increased from 8 to 30 bar. In addition to the visual observation of water beginning to flow rapidly from the fracture at $30 \mathrm{bar}$, the flow rate jumped quickly from $8.8 \mathrm{~mL} / \mathrm{min}$ at 28 bar to $160 \mathrm{~mL} / \mathrm{min}$ at $30 \mathrm{bar}$ when the apparent refracturing event occurred. Calculation methodologies outlined in eqs 5 and 6 were used to estimate the permeability. Before reaching $30 \mathrm{bar}$, when fluids were not observed flowing from the fracture, the permeability was 


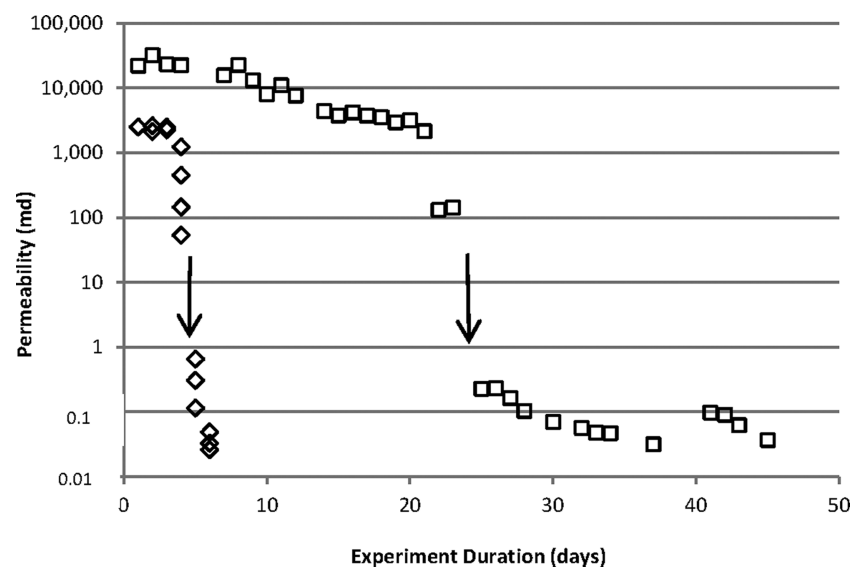

Figure 4. Calculated reduction in permeability from fracture sealing experiments $1(\square)$ and $2(\diamond)$. Arrows indicate when radial rather than fracture dominated flow was observed and also where the transition was made to calculate permeability using eq 6 (full radial flow) as opposed to eq 5 (fracture dominated flow). At day 23 and day 5 (for sealing experiment 1 and sealing experiment 2 , respectively), no fluid flow was observed from the fracture and the injected fluids extended radially from the well. Calculated permeability reduced from approximately $23000 \mathrm{md}$ to approximately $0.1 \mathrm{md}$ in sealing experiment 1 and from approximately $2400 \mathrm{md}$ to approximately 0.1 md in experiment 2. Numerical results are reported as averages of several data points near the beginning and end of each experiment.

calculated using eq 6; at 30 bar with fracture dominated flow, permeability increased and was calculated with eq 5 (Figure 5). Since the packer was likely leaking at 30 bar, the pressure was decreased to 8 bar (not beyond packer's pressure limit) to confirm the refracturing permeability of $\sim 2100 \mathrm{md}$.

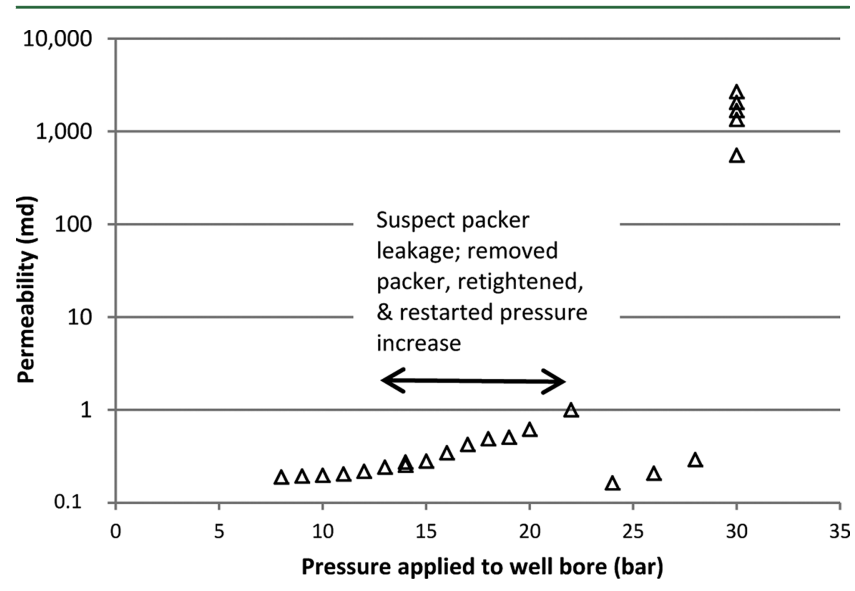

Figure 5. Stepwise increase of applied well bore pressure caused the fracture to re-open at $30 \mathrm{bar}$ after sealing experiment 1 . The calculated permeability increased from $0.2 \mathrm{md}$ to approximately $2100 \mathrm{md}$ after refracturing; an increase of 4 orders of magnitude.

Black light images (Figure S5, Supporting Information) revealed channels where fluorescein-amended fluid flowed after the fracture reopened. The refracture flow path showed fewer distinct channels, and the second sealing experiment began with permeability reduced from the original hydraulic fracturing event. Because of these observations, it was hypothesized that some of the original pore channels were not reopened or opened with a reduced aperture during the refracturing event.

\section{DISCUSSION}

Toward developing field-scale relevant MICP fracture sealing technologies, an injection strategy was developed to homogenously precipitate $\mathrm{CaCO}_{3}$ and minimize near-injection-point plugging, decrease permeability while increasing the treated strength of a hydraulically fractured mesoscale core and more quickly seal a core fracture. Column data (1-4) discussed within this paper have also been used to calibrate a reactive transport pore-scale ureolysis-driven MICP model which can ultimately assist with further improving injection strategies. ${ }^{22} \mathrm{~A}$ combination of modeling and experimentation is necessary to expand these procedures toward field-relevant scale.

Several researchers have reported higher levels of mineral precipitation near the injection points in columns or other reactor studies. ${ }^{19,20,21,28}$ Extending mineral precipitation homogenously may be advantageous to sealing multiple fractures while preventing near-injection-point plugging. ${ }^{29,30}$ In these studies the extent of $\mathrm{CaCO}_{3}$ precipitation was controlled to prevent near-injection-point plugging by: (1) displacing the available $\mathrm{Ca}^{2+}$ in the injection region during active biomineralization periods, and (2) reducing the saturation conditions immediately prior to calcium-growth media injection to prevent instantaneous precipitation.

Other MICP studies have reported changes in properties of porous materials like increased compressive strength and reduced permeability. ${ }^{19,31-33}$ Sand's compressive strength has been shown to increase to $570 \mathrm{kPa}^{19}$ and permeability was reported to decrease $15-99.9 \%$ because of $\mathrm{CaCO}_{3}$ precipitation in sand-filled reactors or sandstone cores. ${ }^{15,16,19,21,33}$ In the studies reported here, permeability was decreased up to $99 \%$ in columns and 4 orders of magnitude in core fractures. Although column sand compressive strength was not measured here, the MICP treated fracture withstood greater than three times the applied well bore pressure before refracturing.

As other researchers have noted, microbes provide nucleation sites for $\mathrm{CaCO}_{3}$ to precipitate (Supporting Information Figure S6), and $\mathrm{CaCO}_{3}$ precipitation may inactivate microorganisms or create nutrient-diffusion limitations, leading to reduced ureolysis and reduced biomineralization. ${ }^{24,34-36}$ Also, biofilms, particularly the extracellular polymeric substances (EPS), are generally highly hydrated and may create an environment where ions or molecules may accumulate in higher concentrations than the bulk fluid. ${ }^{37}$ As such, maintaining the hydration and ureolytic activity of the biofilm needs to be balanced with the goal of precipitating $\mathrm{CaCO}_{3}$ in shortened, field-relevant, time scales. The shortened duration to seal the core fracture in sealing experiment 2 was possibly due to immediately starting overnight resuscitation phases or increasing the daily number of calcium growth pulses. The faster observed sealing may have also been due to additional nucleation sites available from remaining $\mathrm{CaCO}_{3}$ deposited in the first sealing experiment, fewer open pore channels (as observed from fluorescein tracer images), or lower initial fracture permeability, perhaps indicating smaller overall fracture aperture size.

In consideration of field relevance it is important to question the source of ureolytic organisms in the target formation. Ureolytic organisms may either need to be stimulated (biostimulation) or injected (bioaugmentation). ${ }^{18}$ If injected, organisms must penetrate the pore spaces of target formations, and microbial transport can be restricted by permeability, pore throat size, tortuosity of the matrix, and other complex factors 
such as cell stickiness or electrostatic interactions. ${ }^{18,38,39}$ Should microbial injection rather than biostimulation be necessary, starved bacteria or spores might penetrate more easily and evenly; soil microbes typically are one to two micrometers in length where starved bacteria are smaller, down to a diameter of $0.3 \mu \mathrm{m}$ and more spherical. ${ }^{8,40,41}$ Since microorganisms are small and starved microbes and spores are even smaller, the MICP treatment of small aperture fractures like in the core experiments shown here may be possible with this technology.

In addition, field relevance of MICP fracture sealing also depends on economic feasibility. Assuming the use of similar injection strategies and nutrients presented within this paper but in quantities relevant to large scale fracture sealing or fielddeployment, analytical grade urea, carbon, and calcium sources $(12 \%, 18 \%$, and $22 \%$ of media costs respectively) represent major economic impact factors. Optimizing $\mathrm{Ca}^{2+}$ deposition efficiency and utilizing alternate carbon, urea, and calcium sources such as carbon and calcium-rich industrial waste streams, urea fertilizers, or calcium chloride ice melting products may provide cost savings in large scale ureolysisdriven MICP projects. ${ }^{20,42,43}$

Several challenges exist when considering the use of this technology in relevant subsurface $\mathrm{CO}_{2}$ storage site conditions including elevated temperatures, pressures, and the presence of supercritical $\mathrm{CO}_{2}\left(\mathrm{scCO}_{2}\right)$, a known antimicrobial. In the case of bioaugmentation, the use of certain mesophilic microorganisms will likely limit the sites and depth where this technology might be applied because of temperature limitations. That said, previous evidence suggests that ureolytic organisms grow in highly-saline $\mathrm{e}^{44-46}$ and high pressure environments $^{47}$ and that biofilms are resistant to the antimicrobial effects of $\mathrm{scCO}_{2} \cdot{ }^{48}$ We present evidence that evolving injection strategies produced homogeneous spatial $\mathrm{CaCO}_{3}$ distribution and minimized injection-point plugging in sand-filled columns and reduced permeability in fractured sandstone. This suggests that the biofilm-induced $\mathrm{CaCO}_{3}$ precipitation technology has the potential to seal fractures and improve long-term storage security of geologically sequestered $\mathrm{CO}_{2}$ in subsurface storage sites like deep saline aquifers. Additional research including mesoscale high pressure experiments and modeling will help develop these techniques and improve cost efficiency toward field-scale implementation.

\section{ASSOCIATED CONTENT}

\section{S Supporting Information}

Additional method details, core porosity, permeability, and pore throat characterization, thin section analysis, XRD results of scraped core materials, effluent ammonium concentrations of core sealing experiment 1 , and black light images of fracture flow channels. This material is available free of charge via the Internet at http://pubs.acs.org.

\section{ACKNOWLEDGMENTS}

Funding was provided from the US Department of Energy (DOE) under NETL DE-FE0004478 with matching support from Southern Company Generation. Additional financial support was provided by the Zero Emissions Research Technology Center (ZERT), Award No. DE-FC2604NT42262 and DOE EPSCoR Award No. DE-FG0208ER46527. Any opinions, findings, conclusions, or recommendations expressed herein are those of the authors and do not necessarily reflect the views of the DOE. We acknowledge Shell International Exploration and Production B.V. for technical advice and oversight. Support for the Environmental and Biofilm Mass Spectrometry Facility through DURIP, Contract Number: W911NF0510255 and the MSU Thermal Biology Institute from the NASA Exobiology Program Project NAG5-8807 is acknowledged. Acknowledgments go to Dr. Isaac Klapper, Dr. Peter Walsh and Randy Hiebert for assistance with permeability calculation methodology and core characteristic measurements. Appreciation is extended to Lance Kitchens of Russo Corporation for core procurement and David Kopaska-Merkel at the Geological Survey of Alabama for thin section analysis. Thanks also to undergraduate engineering researchers Jordan Kennedy, Joshua Stringam, Dayla Morris, and Adam Rothman. The authors thank the anonymous reviewers and the editors for their guidance and support in revising this manuscript.

\section{REFERENCES}

(1) Sausse, J.; Jacquot, E.; Fritz, B.; Leroy, J.; Lespinasse, M. Evolution of crack permeability during fluid-rock interaction. Example of the Brézouard granite (Vosges, France). Tectonophysics 2001, 336 (1-4), 199-214.

(2) Zhang, X.; Jeffrey, R. G.; Bunger, A. P.; Thiercelin, M. Initiation and growth of a hydraulic fracture from a circular wellbore. Int. J. Rock Mech. Min. Sci. 2011, 48 (6), 984-995.

(3) Huerta, N. J.; Bryant, S. L.; Conrad, L. Cement core experiments with a conductive leakage pathway, under confining stress and alteration of cement's mechanical properties via a reactive fluid, as an analog for $\mathrm{CO}_{2}$ leakage scenario. In SPE/DOE Symposium on Improved Oil Recovery;, Society of Petroleum Engineers: Tulsa, OK., 2008; Vol. SPE 113375-MS.

(4) Wigand, M.; Kaszuba, J. P.; Carey, J. W.; Hollis, W. K. Geochemical effects of $\mathrm{CO}_{2}$ sequestration on fractured wellbore cement at the cement/caprock interface. Chem. Geol. 2009, 265 (1-2), $122-133$.

(5) Esposito, A.; Benson, S. M. Remediation of possible leakage from geologic $\mathrm{CO}_{2}$ storage reservoirs into groundwater aquifers. Energy Procedia 2011, 4, 3216-3223.

(6) Carroll, S.; McNab, W.; Torres, S.; Singleton, M.; Zhao, P. Wellbore integrity in carbon sequestration environments: 1 . Experimental study of Cement-Sandstone/Shale-Brine- $\mathrm{CO}_{2}$. Energy Procedia 2011, 4, 5186-5194.

(7) Mitchell, A.; Phillips, A.; Hiebert, R.; Gerlach, R.; Spangler, L.; Cunningham, A. Biofilm enhanced geologic sequestration of supercritical $\mathrm{CO}_{2}$. Int. J. Greenhouse Gas Control 2009, 3, 90-99.

(8) MacLeod, F. A.; Lappin-Scott, H. M.; Costerton, J. W. Plugging of a model rock system using starved bacteria. Appl. Environ. Microbiol. 1988, 54 (6), 1365-1372.

(9) Mitchell, A. C.; Didericksen, K.; Spangler, L. H.; Cunningham, A. B.; Gerlach, R. Microbially enhanced carbon capture and storage by mineral-trapping and solubility-trapping. Environ. Sci. Technol. 2010, 44 (13), 5270-5276.

(10) Hammes, F.; Boon, N.; de Villiers, J.; Verstraete, W.; Siciliano, $\mathrm{S}$. Strain-specific ureolytic microbial calcium carbonate precipitation. Appl. Environ. Microbiol. 2003, 69 (8), 4901-4909. 
(11) Mobley, H. L. T.; Hausinger, R. P. Microbial UreasesSignificance, Regulation, and Molecular Characterization. Microbiol. Rev. 1989, 53 (1), 85-108.

(12) Ferris, F.; Phoenix, V.; Fujita, Y.; Smith, R. Kinetics of calcite precipitation induced by ureolytic bacteria at 10 to 20 degrees $\mathrm{C}$ in artificial groundwater. Geochim. Cosmochim. Acta 2003, 67 (8), 17011710.

(13) Cuthbert, M. O.; Riley, M. S.; Handley-Sidhu, S.; Renshaw, J. C.; Tobler, D. J.; Phoenix, V. R.; Mackay, R. Controls on the rate of ureolysis and the morphology of carbonate precipitated by S. Pasteurii biofilms and limits due to bacterial encapsulation. Ecol. Eng. 2012, 41 (0), 32-40.

(14) De Muynck, W.; De Belie, N.; Verstraete, W. Microbial carbonate precipitation in construction materials: A review. Ecol. Eng. 2010, 36 (2), 118-136.

(15) Ferris, F.; Stehmeier, L.; Kantzas, A.; Mourits, F. Bacteriogenic mineral plugging. J. Can. Pet. Technol. 1996, 35, 56-61.

(16) Gollapudi, U. K.; Knutson, C. L.; Bang, S. S.; Islam, M. R. A new method for controlling leaching through permeable channels. Chemosphere 1995, 30 (4), 695-705.

(17) Al-Thawadi, S. M. Ureolytic bacteria and calcium carbonate formation as a mechanism of strength enhancement of sand. J. Adv. Sci. Eng. Res. 2011, 1, 98-114.

(18) DeJong, J. T.; Mortensen, B. M.; Martinez, B. C.; Nelson, D. C. Bio-mediated soil improvement. Ecol. Eng. 2010, 36 (2), 197-210.

(19) Whiffin, V.; van Paassen, L.; Harkes, M. Microbial carbonate precipitation as a soil improvement technique. Geomicrobiol. J. 2007, 24, 417-423.

(20) Achal, V.; Mukherjee, A.; Basu, P.; Reddy, M. Lactose mother liquor as an alternative nutrient source for microbial concrete production by Sporosarcina pasteurii. J. Ind. Microbiol. Biotechnol. 2009, 36, 433-438.

(21) Cunningham, A. B.; Gerlach, R.; Spangler, L.; Mitchell, A. C.; Parks, S.; Phillips, A. Reducing the risk of well bore leakage of $\mathrm{CO}_{2}$ using engineered biomineralization barriers. Energy Procedia 2011, 4, $5178-5185$.

(22) Ebigbo, A.; Phillips, A.; Gerlach, R.; Helmig, R; Cunningham, A. B.; Class, H.; Spangler, L. H. Darcy-scale modeling of microbially induced carbonate mineral precipitation in sand columns. Water Resour. Res. 2012, 48 (7), W07519.

(23) Herigstad, B.; Hamilton, M.; Heersink, J. How to optimize the drop plate method for enumerating bacteria. J. Microbiol. Methods 2001, 44 (2), 121-129.

(24) Bachmeier, K. L.; Williams, A. E.; Warmington, J. R.; Bang, S. S. Urease activity in microbiologically-induced calcite precipitation. J. Biotechnol. 2002, 93 (2), 171-181.

(25) Todd, D.; Mays, L., Groundwater Hydrology, 3rd ed.; John Wiley and Sons, Inc.: New York, U.S.A., 2005

(26) Wheeler, L. A. Establishment of ureolytic biofilms and their influence on the permeability of pulse-flow porous media column systems. Master's Thesis. Montana State University, Bozeman, MT, 2009.

(27) Gangi, A. F. Variation of whole and fractured porous rock permeability with confining pressure. Int. J. Rock Mech. Min. Sci. Geomech. Abstr. 1978, 15 (5), 249-257.

(28) Schultz, L.; Pitts, B.; Mitchell, A. C.; Cunningham, A. B.; Gerlach, R. Imaging biologically-induced mineralization in fully hydrated flow systems. Microsc. Today, Jan. 2011 2011, 19 (5), 10-13.

(29) Harkes, M. P.; van Paassen, L. A.; Booster, J. L.; Whiffin, V. S.; van Loosdrecht, M. C. M. Fixation and distribution of bacterial activity in sand to induce carbonate precipitation for ground reinforcement. Ecol. Eng. 2010, 36 (2), 112-117.

(30) Fujita, Y.; Taylor, J.; Gresham, T.; Delwiche, M.; Colwell, F.; McLing, T.; Petzke, L.; Smith, R. Stimulation of microbial urea hydrolysis in groundwater to enhance calcite precipitation. Environ. Sci. Technol. 2008, 42, 3025-3032.

(31) van Paassen, L.; Ghose, R.; van der Linden, T.; van der Star, W.; van Loosdrecht, $\mathrm{M}$. Quantifying biomediated ground improvement by ureolysis: Large-scale biogrout experiment. J. Geotech. Geoenviron. Eng. 2010, 136 (12), 1721-1728.

(32) DeJong, J. T. Microbially induced cementation to control sand response to undrained shear. J. Geotech. Geoenviron. Eng. 2006, 132 (11), 1381.

(33) Nemati, M.; Voordouw, G. Modification of porous media permeabilty, using calcium carbonate produced enzymatically in situ. Enzyme Microb. Technol. 2003, 33, 635-642.

(34) De Muynck, W.; Verbeken, K.; De Belie, N.; Verstraete, W. Influence of urea and calcium dosage on the effectiveness of bacterially induced carbonate precipitation on limestone. Ecol. Eng. 2010, 36 (2), 99-111.

(35) Dupraz, S.; Menez, B.; Gouze, P.; Leprovost, R.; Benezeth, P.; Pokrovsky, O.; Guyot, F. Experimental approach of $\mathrm{CO}_{2}$ biomineralization in deep saline aquifers. Chem. Geol. 2009, 265, 54-62.

(36) Stocks-Fischer, S.; Galinat, J.; Bang, S. Microbiological precipitation of $\mathrm{CaCO}_{3}$. Soil Biol. Biochem. 1999, 31 (11), 1563-1571.

(37) Decho, A. W. Overview of biopolymer-induced mineralization: What goes on in biofilms? Ecol. Eng. 2010, 36 (2), 137-144.

(38) Jenneman, G.; McInerney, M.; Knapp, R. Microbial penetration through nutrient-saturated berea sandstone. Appl. Environ. Microbiol. 1985, 50 (2), 383-391.

(39) Bouwer, E.; Rijnaarts, H.; Cunningham, A.; Gerlach, R., Biofilms in porous media. In Biofilms II: Process Analysis and Applications; Bryers, J., Ed.; Wiley-Liss, Inc.: New York, U.S.A.2000; pp 123-158.

(40) Gerlach, R.; Cunningham, A. B., Influence of biofilms on porous media. In Porous Media: Applications in Biological Systems and Biotechnology; Vafai, K., Ed.; Taylor and Francis: Florida, U.S.A., 2011; pp 173-230.

(41) Cunningham, A. B.; Sharp, R. R.; Caccavo, F., Jr; Gerlach, R. Effects of starvation on bacterial transport through porous media. Adv. Water Resources 2007, 30 (6-7), 1583-1592.

(42) Achal, V.; Mukherjee, A.; Reddy, M. Effect of calcifying bacteria on permeation properties of concrete structures. J. Ind. Microbiol. Biotechnol. 2011, 38 (9), 1229.

(43) Burbank, M. B.; Weaver, T. J.; Green, T. L.; Williams, B. C.; Crawford, R. Precipitation of calcite by indigenous microorganisms to strengthen liquefiable soils. Geomicrobiology Journal 2011, 28 (4), 301-312.

(44) Mortensen, B.; Haber, M.; DeJong, J.; Caslake, L.; Nelson, D. Effects of environmental factors on microbial induced calcium carbonate precipitation. J. Appl. Microbiol. 2011, 111 (2), 338-349.

(45) Tobler, D. J.; Cuthbert, M. O.; Greswell, R. B.; Riley, M. S.; Renshaw, J. C.; Handley-Sidhu, S.; Phoenix, V. R. Comparison of rates of ureolysis between Sporosarcina pasteurii and an indigenous groundwater community under conditions required to precipitate large volumes of calcite. Geochim. Cosmochim. Acta 2011, 75 (11), 3290-3301.

(46) Dupraz, S.; Parmentier, M.; Menez, B.; Guyot, F. Experimental and numerical modeling of bacterially induced $\mathrm{pH}$ increase and calcite precipitation in saline aquifers. Chem. Geol. 2009, 265, 44-53.

(47) Mitchell, A. C.; Phillips, A. J.; Schultz, L.; Parks, S.; Spangler, L.; Cunningham, A. B.; Gerlach, R. Microbial $\mathrm{CaCO}_{3}$ mineral formation and stability in a simulated high pressure saline aquifer with supercritical $\mathrm{CO}_{2}$. I. J. Greenhouse Gas Control 2012, Ref. no. JGGCD-12-00155.

(48) Mitchell, A. C.; Phillips, A. J.; Hamilton, M. A.; Gerlach, R.; Hollis, W. K.; Kaszuba, J. P.; Cunningham, A. B. Resilience of planktonic and biofilm cultures to supercritical $\mathrm{CO}_{2}$. J. Supercrit. Fluids 2008, 47 (2), 318-325.

\section{NOTE ADDED AFTER ASAP PUBLICATION}

The Supporting Information file in the version of this paper published August 22, 2012 was revised with additional experimental details. The correct file published August 27, 2012. 